\title{
Constitución de cajas menores en entidades territoriales. Un límite a la discrecionalidad administrativa*
}

\author{
Constitution of petty cash in territorial entities. A limit to administrative discretion
}

\author{
Cesar Augusto Lucas Ortegón a \\ Universidad Pedagógica y Tecnológica de Colombia, \\ Colombia \\ cesarlucaso70@hotmail.com \\ ORCID: http://orcid.org/0000-0002-0016-9274
}

DOI: https://doi.org/10.11144/Javeriana.cc19-48.ccme Redalyc: http://www.redalyc.org/articulo.oa? $\mathrm{id}=151557795001$

Fecha de recepción: 17 Abril 2017 Fecha de aprobación: 11 Septiembre 2018 Fecha de publicación: 20 Diciembre 2018

\section{Resumen:}

Este artículo analiza si en Colombia las entidades territoriales pueden, mediante acto administrativo, constituir y reglamentar el funcionamiento de cajas menores a la luz del principio de autonomía que les confiere la Constitución Política; o si, por el contrario, deben ceñirse a lo que establece el Presupuesto de Rentas y Ley de Apropiaciones, lo cual implicaría la ilegalidad absoluta de las cajas menores constituidas por entes territoriales y por ende la ilegalidad de los actos que se celebren con base en ellas. Se utilizó una metodología de tipo inductivo, en la cual se avanzó a partir del análisis normativo y jurisprudencial de la caja menor como institución jurídica, así como un estudio del principio de autonomía territorial y sus límites. Se concluye que las entidades territoriales están imposibilitadas constitucional y legalmente para instituir y reglamentar cajas menores. Palabras clave: caja menor, entidades territoriales, autonomía territorial, presupuesto público.

\begin{abstract}
:
This article analyzes if in Colombia the territorial entities can, by means of administrative act, constitute and regulate the operation of petty cash in light of the principle of autonomy that the Political Constitution confers them; or if, on the contrary, they must adhere to what is established in the Budget of Revenues and the Law of Appropriations, which would imply the absolute illegality of the petty cash constituted by territorial entities, and therefore the illegality of the acts that are celebrated based on upon them. An inductive type of methodology was used, in which progress was made based on the normative and jurisprudential analysis of petty cash as a legal institution, as well as a study of the principle of territorial autonomy and its limits. It is concluded that territorial entities are constitutionally and legally unable to institute and regulate petty cash. Keywords: petty cash, territorial entities, territorial autonomy, public budget.
\end{abstract}

\section{Introducción}

El mecanismo conocido como caja menor fue creado por el Presupuesto de Rentas y Ley de Apropiaciones, en

su connotación jurídica, con base en lo establecido tanto en el artículo 150, numeral 11, como en el artículo 346 de la Constitución Política de 1991. Esta norma permite que los organismos y entidades que conforman el Presupuesto General de la Nación constituyan anualmente esta herramienta presupuestal que les permita sufragar gastos identificados y definidos como urgentes. Para el efecto, la Ley 21 de 1992 en el artículo 19 estableció:

La constitución y funcionamiento de las cajas menores y la utilización de los avances de los organismos y entidades del Presupuesto General de la Nación, requerirá de la reglamentación por parte del Ministerio de Hacienda, Dirección General del Presupuesto, la cual deberá expedirse a más tardar el 15 de febrero de 1993. (Ley 21 de 1992, art. 19)

Notas de autor

a Autor de correspondencia. Correo electrónico: cesarlucaso70@hotmail.com 
El artículo es claro en establecer el margen de aplicación normativo a los organismos y entidades del Presupuesto General de la Nación, la ley en comento no hace extensiva la caja menor a otros organismos y entidades del Estado. Sin embargo, las entidades territoriales recurren al principio de la analogía, y con base en la reglamentación que expiden anualmente el Ministerio de Hacienda y demás organismos y entidades que conforman el Presupuesto General de la Nación, profieren un acto administrativo en el cual crean y reglamentan la Caja Menor para su ente territorial, sin tener en cuenta que carecen de facultades legales para ello.

Este artículo analiza si las entidades territoriales pueden, mediante acto administrativo, constituir y reglamentar el funcionamiento de cajas menores a la luz del principio de autonomía que les confiere la Constitución Política, o si por el contrario, deben ceñirse a lo que establece el Presupuesto de Rentas y Ley de A propiaciones, lo cual implicaría la ilegalidad absoluta de las cajas menores constituidas por entes territoriales y por ende la ilegalidad de los actos que se celebren con base en ellas. Se utilizó una metodología de carácter inductivo, en la cual se avanzó desde la generalidad de la norma jurídica y la teoría propia del tema, para lograr abarcar el problema planteado.

El artículo se desarrolla en el siguiente orden: en la primera parte se abordan el concepto y las características de las entidades territoriales con el fin de precisar el alcance de su autonomía; en la segunda parte se expone lo relacionado con las entidades y organismos facultados normativamente para constituir cajas menores y las discrepancias al respecto; y finalmente, en la tercera se presentan algunos casos que evidencian el vacío conceptual respecto a lo que precisan las normas y que induce a actos administrativos en contrario.

\section{Definición y características de las entidades territoriales}

El artículo 286 de la Carta Política establece que son entidades territoriales los departamentos, los distritos, los municipios y los territorios indígenas. Sin embargo, para aproximarnos a una definición real de entidad territorial en el contexto de la organización político-administrativa, se debe entender al Estado como una persona jurídica de derecho público, normada por la ley (C.P., art. 1), que en los términos del Código Civil es:

una persona ficticia, capaz de ejercer derechos y contraer obligaciones civiles, y de ser representada judicial y extrajudicialmente. Las personas jurídicas son de dos especies: corporaciones y fundaciones de beneficencia pública. Hay personas jurídicas que participan de uno y otro carácter. (Código Civil, art. 633)

Frente a ello, cabe resaltar como la norma citada clarifica que la naturaleza de esta figura es la de una persona moral, distinta a la persona natural; lo cual significa que el Estado como persona jurídica, goza de derechos y es capaz de contraer obligaciones y posee los mismos atributos de la personalidad que la ley le confiere a estas últimas.

En igual sentido, es claro que el Estado, como persona jurídica, está diseñado en función de unos fines constitucionales que se encuentran consagrados en el artículo segundo de la Carta, los cuales son esencialmente:

(i) Servir a la comunidad, promover la prosperidad general, y garantizar la efectividad de los principios, derechos y deberes constitucionales; (ii) facilitar la participación de todos en las decisiones que los afectan y en la vida económica, política, administrativa, y cultural de la Nación; (iii) defender la independencia nacional, mantener la integridad territorial, y asegurar la convivencia pacífica y la vigencia de un orden justo. (C.P., art. 2)

Así mismo, está estructurado jerárquicamente para el cumplimiento de esos fines (figura 1) de acuerdo con lo normado en la parte orgánica de la Constitución. 


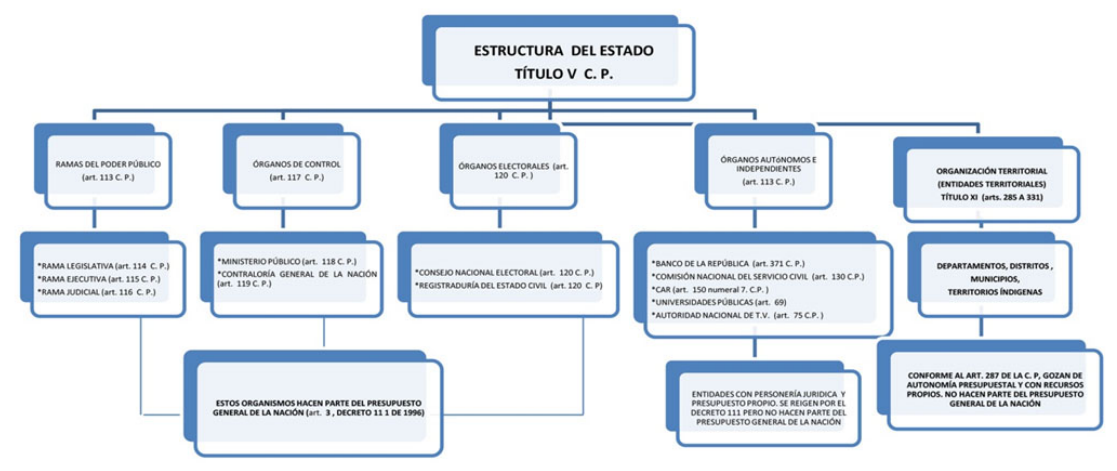

Figura 1. Estructura del Estado colombiano.

Fuente: elaboración propia.

La estructura del poder público en Colombia se rige por algunos principios que operan como fundamento organizacional de cualquier Estado. Según Rodríguez (2012) estos principios se pueden resumir así:

a) Separación de poderes.

b) El Estado federal y el Estado unitario.

c) Los principios básicos de la estructura y funcionamiento del Estado unitario.

d) El principio de centralización política y descentralización administrativa.

Para los efectos del tema del presente artículo, la atención se centra en lo relativo a la estructura y funcionamiento del Estado unitario. Para esto analizamos con detalle lo dispuesto en el artículo 209 de la Carta Superior: descentralización, delegación y desconcentración de funciones.

La Descentralización en un sentido amplio se puede definir como la facultad que otorgan la Constitución, el Decreto Ley 1222 de 1986 y el Decreto Ley 1333 de 1986 al Estado para crear personas jurídicas públicas con funciones que podrán ejercer autónomamente, en su propio nombre y bajo su propia responsabilidad. (C.P., art. 1), (Dcto. 1222/1986 art. 4), (Dcto. 1333/1986 art. 3).

La jurisprudencia de la Corte Constitucional y del Consejo de Estado ha determinado que, si bien la desconcentración y la descentralización conllevan otorgamiento de funciones, existen diferencias tangenciales entre las dos figuras, ya que, mientras en la primera la entidad nacional encarga en su agente funciones propias, en la segunda el Estado distribuye sus competencias entre personas jurídicas diferentes, sin perjuicio del necesario control administrativo. Dichas personas son elegidas por la misma comunidad y operan bajo el control del poder central (Ver Corte Constitucional, sentencias T-024 de 1996, C-496 de 1998 y C-036 de 2005 y Consejo de Estado, sentencias 14 mayo 1985, S2a, exp. 10274 y 24 agosto 1994, S2a, exp. 8183).

La Delegación. De acuerdo con la Ley 489 de 1998, la delegación consiste en la facultad que tienen las autoridades administrativas para "transferir el ejercicio de funciones a sus colaboradores o a otras autoridades, con funciones afines o complementarias" (Ley 489/1998 art.4). El acto de delegación debe cumplir con los requisitos señalados en los artículos 10 y 11 de la Ley 489 de 1998: a) que sea por escrito, y b) que se determine la autoridad delegataria y las funciones o asuntos específicos cuya atención y decisión se transfieren.

Es importante anotar que la delegación exime de responsabilidad al delegante, y que en cualquier tiempo el delegatario puede reasumir la competencia y revisar los actos expedidos por el delegatario. Igualmente, existen eventos en los que la Ley 489 no permite que se exima de responsabilidad civil, penal, administrativa y fiscal al delegatario, como en el caso de la contratación estatal (Ley 489/1998 art. 12).

Precisamente, la figura administrativa de la delegación es la que da lugar al manejo de la caja menor por parte de los organismos o entidades que hacen parte del Presupuesto General de la Nación, únicos facultados por la ley para tal operación.

La Desconcentración. El artículo 8 de la Ley 489 de 1998 establece que la desconcentración consiste en "la radicación de competencias y funciones en dependencias ubicadas fuera de la sede principal del organismo o 
entidad administrativa, sin perjuicio de las potestades y deberes de orientación e instrucción que corresponde ejercer a los jefes superiores de la administración" (Ley 489/1998 art. 8).

La desconcentración se puede clasificar en territorial, es decir, la que se acaba de definir, y la jerárquica o funcional que consiste en el otorgamiento de funciones de las autoridades superiores a las inferiores, sin que se dé el desplazamiento físico; como sí ocurre en la desconcentración territorial.

$\mathrm{Al}$ igual que la delegación, la desconcentración permite que un órgano, un organismo o una entidad que hace parte del presupuesto general de la nación puedan optar por el manejo de la caja menor en los términos que establece el gobierno nacional.

\section{Características de las entidades territoriales}

Con esta información se pueden caracterizar las entidades territoriales, así:

Las entidades territoriales son personas jurídicas de derecho público. En Colombia, según el artículo 73 del Código Civil las personas son naturales o jurídicas, sujetos de derecho, es decir, cuentan con capacidad de goce y de ejercicio dentro del ordenamiento jurídico. De acuerdo con los Decretos 1333/1986 (art. 4) y 1222/1986 (art. 3), la nación, los departamentos, las intendencias, las comisarías y los municipios tienen personería jurídica y por consiguiente están facultados para adquirir derechos, contraer obligaciones y ser representados judicial y extrajudicialmente.

Es importante anotar que la personería jurídica pública o privada solamente se adquiere por mandato de la Constitución Política, como es el caso del Banco de la República en virtud del artículo 371; de la Ley, siendo ejemplo de ello la personería jurídica que otorga el artículo 57 de la Ley 30 de 1992 a los entes universitarios autónomos y/o del Reglamento, muestra de ello será el artículo 316 del Decreto 663 de 1994, relativo al Fondo de Garantías de Instituciones Financieras.

Hay que destacar que las personas jurídicas pueden ser tanto de derecho público como de derecho privado. Estas últimas tienen una regulación distinta, así como otros fines y funciones, ya que, mientras las de derecho público buscan el beneficio común, las de derecho privado pueden funcionar con o sin ánimo de lucro, dependiendo de su objeto y razón social (Angarita, 2005).

- Los entes territoriales tienen a su cargo competencias y funciones de tipo administrativo que deben ejecutar bajo su responsabilidad.

Concretamente el Título XI de la Constitución Política, atinente a la organización territorial, establece en el artículo 287 los derechos de dichas entidades y en el artículo 288 determina que será la ley orgánica de ordenamiento territorial la que establezca la distribución de competencias entre estas y la nación.

En concordancia con esto, y en aras de establecer las competencias y funciones de tipo administrativo de las entidades territoriales, el Congreso de la República expidió en el año 2011 la Ley 1454, conocida como Ley Orgánica de Ordenamiento Territorial. Dicho ordenamiento es definido como un instrumento de planificación y de gestión de las entidades territoriales y un proceso de construcción colectiva de país, que se da de manera progresiva, gradual y flexible con responsabilidad fiscal.

La norma determina que la planificación y la gestión de las entidades territoriales deberá hacerse para facilitar el desarrollo institucional, el fortalecimiento de la identidad cultural y el desarrollo territorial; que su finalidad es promover el aumento de la capacidad de descentralización, planeación, gestión y administración; el fomento del traslado de las competencias y el poder de decisión de los órganos centrales o descentralizados del gobierno nacional hacia el nivel territorial pertinente, con la correspondiente asignación de recursos; y propiciar las condiciones para establecer y determinar las políticas públicas entre la Nación y las entidades territoriales, con reconocimiento de la diversidad geográfica, histórica, económica ambiental, étnica y cultural e identidad regional y nacional. 
Adicionalmente, el artículo 3 de la Ley 1454 establece como principios del proceso de ordenamiento territorial los siguientes: soberanía y unidad nacional, autonomía, descentralización, integración, regionalización, sostenibilidad, participación, solidaridad y equidad territorial, diversidad, gradualidad y flexibilidad, prospectiva, paz y convivencia, asociatividad, responsabilidad y transparencia, equidad social y equilibrio territorial, economía y buen gobierno, y multietnicidad.

- Gozan de una autonomía sometida a los límites establecidos en la Constitución y la ley.

Como ya se dijo, la Constitución Política de 1991 se ocupa de la autonomía de las entidades territoriales en los artículos 1, 2, 287 y dedica el título XI a la organización territorial: carácter, derechos, competencias y regímenes.

También lo dispone el artículo 28 de la Ley 1454 de 2011 al indicar que:

Los departamentos y municipios tendrán autonomía para determinar su estructura interna y organización administrativa central y descentralizada; así como el establecimiento y distribución de sus funciones y recursos para el adecuado cumplimiento de sus deberes constitucionales.

Sin perjuicio de su control de constitucionalidad o de legalidad, estos actos no estarán sometidos a revisión, aprobación, o autorización de autoridades nacionales. (Ley 1454/20141 art. 28)

Sin embargo, no se puede hablar de autonomía territorial sin hacer previa mención al municipio como entidad territorial básica del modelo de organización territorial colombiana así como a su evolución y desarrollo.

Según Henao (2015) los españoles fueron los que instituyeron la figura del municipio como entidad territorial en nuestro continente, teniendo en cuenta que en el país ibérico ya se tenía este modelo administrativo territorial, sin perjuicio de la existencia de un centralismo y un federalismo marcado notoriamente.

Fue hasta el siglo xix cuando en la Nueva Granada, tras la independencia, se dio el primer fragmento de lo que hoy se conoce como la municipalidad, figura marcada por raigambre de centralismo absoluto, aunque permitiéndose visos de autonomía territorial para el manejo de sus intereses.

La crisis por la que atravesaba el Estado colombiano en 1983 hizo necesarios unos cambios en el modelo administrativo; en el caso del municipio requirió desarrollar algunas alternativas para el cumplimiento de los fines estatales dando origen al principio de la autonomía territorial bajo tres órbitas distintas: política, fiscal y administrativa. A nivel político implicó establecer normativas de elección popular de los mandatarios locales; por otro lado, en materia fiscal se implementaron impuestos municipales para hacer posible la autonomía presupuestal y a nivel administrativo, las normas específicas para la gestión y orden de los entes territoriales consolidaron de manera evidente el principio de autonomía territorial. También fueron asignadas funciones, garantías y derechos para el ejercicio de la autonomía, principio al que la Corte Constitucional se ha referido en los siguientes términos:

La territorialidad y la unidad nacional son dos elementos teleológicamente inescindibles, ontológicamente diferenciables a partir de su materialidad geográfica, con unos destinatarios comunes -los habitantes de país-, y por entero, instancias orgánicas y funcionales de un mismo mecanismo estatal: el de la República unitaria, descentralizada, con autonomía de sus entidades territoriales, democrática, participativa y pluralista. (Sentencia C-127/2002)

En igual sentido, y tal como lo advierte Rodríguez Cruz (2014, p. 281), es importante diferenciar el principio de autonomía de otros principios constitucionales, con los cuales tiende a confundirse: Sobre la definición del principio de la autonomía territorial la Corte resaltó la calidad de autonomía propio de quien "decide por sí mismo", sin ser este concepto sinónimo de soberanía o de "grado máximo de libertad”... El concepto de autonomía "hace(n) referencia a un cierto grado de libertad en la toma de decisiones por parte de un determinado ente jurídico en relación con otro”. (Sentencia C-517/1992)

Dicha diferenciación debe desarrollarse a la luz de la autonomía territorial y república unitaria; y la autonomía territorial y descentralización administrativa, a partir de lo cual se puede deducir que la autonomía territorial y el principio de la república unitaria han tenido convergencias y divergencias, toda vez que si se 
analiza el artículo primero de la Constitución Política, es claro que si bien establece un principio de autonomía en sus entidades territoriales, a la vez determina la existencia de una república unitaria.

A raíz del principio de la autonomía territorial que detalla la Carta Magna-Título XI “De la organización territorial" que desarrolla en cuatro capítulos-, el máximo Tribunal Constitucional establece: "La autonomía a los municipios solo tiene sentido en la medida en que les permita cumplir las tareas que la Constitución les ha señalado y que tienen por fin el mejoramiento social y cultural de sus habitantes" (Sentencia C-545/1993).

Estos antecedentes muestran la necesidad de investir a esta organización territorial de facultades propias en beneficio de la comunidad.

El máximo órgano constitucional consideró que la autonomía debía entenderse como la capacidad de que gozan las entidades territoriales para gestionar sus propios intereses, dentro de los límites de la Constitución y la ley. Esto quiere decir que si bien, por un lado, se afirman los intereses locales; por el otro se reconoce la supremacía de un ordenamiento superior, con lo cual la autonomía de las entidades territoriales no se configura como poder soberano sino que se explica en un contexto unitario (C.Const., C-535/1996).

Así también, este mismo órgano en sentencia del 04 de marzo de 2010 recogió los criterios jurisprudenciales sobre los principios que la Constitución Política consagra en el artículo 288, y obliga a que las competencias atribuidas a los distintos niveles territoriales se ejerzan en los términos que establezca la ley, para lo cual estableció: "Para los asuntos de interés meramente local o regional, deben preservase las competencias de los órganos territoriales correspondientes, al paso que cuando se trascienda ese ámbito, corresponde a la ley regular la materia" (C.Const., C-149/2010).

De la misma manera, señaló esta posición jurisprudencial que los principios que obran como marco para el ejercicio de la autonomía territorial son: concurrencia, coordinación y subsidiariedad.

El principio de concurrencia parte de la consideración de que, en determinadas materias, la actividad del Estado debe cumplirse con la participación de los distintos niveles de la Administración. Ello implica, en primer lugar, un criterio de distribución de competencias conforme al cual las mismas deben atribuirse a distintos órganos, de manera que se garantice el objeto propio de la acción estatal, sin que sea posible la exclusión de entidades que, en razón de la materia estén llamadas a participar. De este principio, por otra parte, se deriva también un mandato conforme al cual las distintas instancias del Estado deben actuar allí donde su presencia sea necesaria para la adecuada satisfacción de sus fines, sin que puedan sustraerse de esa responsabilidad.

El principio de coordinación, a su vez, tiene como presupuesto la existencia de competencias concurrentes entre distintas autoridades del Estado, lo cual impone que su ejercicio se haga de manera armónica, de modo que la acción de los distintos órganos resulte complementaria y conducente al logro de los fines de la acción estatal. Esa coordinación debe darse desde el momento mismo de la asignación de competencias y tiene su manifestación más clara en la fase de ejecución de las mismas.

El principio de subsidiariedad, finalmente, corresponde a un criterio, tanto para la distribución y como para el ejercicio de las competencias. Desde una perspectiva positiva significa que la intervención el Estado, y la correspondiente atribución de competencias, debe realizarse en el nivel más próximo al ciudadano, lo cual es expresión del principio democrático y un criterio de racionalización administrativa, en la medida en que son esas autoridades las que mejor conocen los requerimientos ciudadanos. A su vez, en su dimensión negativa, el principio de subsidiariedad significa que las autoridades de mayor nivel de centralización sólo pueden intervenir en los asuntos propios de las instancias inferiores cuando éstas se muestren incapaces o sean ineficientes para llevar a cabo sus responsabilidades. (C.Const., C-149/2010, J. Palacios)

En desarrollo del segundo elemento: autonomía territorial y descentralización administrativa, se puede afirmar que la Constitución Política de Colombia marca la descentralización administrativa como una forma por medio de la cual se estructura la organización del Estado.

La descentralización es una institución jurídica que desciende del artículo 209 de la Constitución Política, al determinar que es un medio para cumplir con la función administrativa, pero la Carta Superior no la define, dejándole esa labor a la ley y a la doctrina administrativa. Sin embargo, la Ley 489 de 1998 tampoco la define. Es la doctrina administrativa, concretamente Rodríguez (2012) quien no solo la define, sino que desde un punto de vista general la presenta como "la facultad que se le otorga a las entidades públicas distintas del Estado para gobernarse por sí mismas, mediante la radicación de funciones en sus manos para que las ejerzan autónomamente" (Rodríguez, 2012, p. 27). 
La descentralización, según Rodríguez (2012), confluye para estos efectos en la descentralización administrativa, la cual presenta tres modalidades: la descentralización territorial, la descentralización especializada o por servicios y descentralización por colaboración, todas respaldadas en línea jurisprudencial de la Corte Constitucional (Ver sentencias C-1051/2001, C-1258/2001, C-889/2002 y C-063/2005).

Para el desarrollo de este aspecto es pertinente esbozar algunos elementos característicos de cada una de estas modalidades:

1. La descentralización territorial, definida por la doctrina administrativa como el otorgamiento de competencias o funciones administrativas a las colectividades regionales o locales, para que las ejerzan en su propio nombre y bajo su propia responsabilidad (Rodríguez, 2012, p. 37). Tiene unos elementos propios, como son las necesidades locales, personería jurídica, autonomía presupuestal y financiera, autonomía administrativa, autoridades locales, control del poder central. Un ejemplo claro de esta son las entidades territoriales.

2. La descentralización especializada o por servicios, también definida por Rodríguez (2012) como el otorgamiento de competencias o funciones de la administración a entidades que se crean para ejercer una actividad especializada. Tiene unos elementos propios como son la existencia de una actividad especial digna de autonomía, personería jurídica, autonomía presupuestal y financiera, autonomía administrativa, autoridades propias, control del poder central. Un ejemplo de esta son los establecimientos públicos, las empresas industriales y comerciales del Estado, las sociedades de economía mixta, las superintendencias y unidades administrativas especiales con personería jurídica, las empresas sociales del Estado, las empresas oficiales de servicios públicos y demás entidades creadas por la ley o con su autorización, cuyo objeto sea el ejercicio de funciones administrativas y la prestación de servicios públicos.

3. La descentralización por colaboración, que Rodríguez (2012, p. 32) define como el otorgamiento de competencias o funciones de la administración a particulares para que la ejerzan a nombre de ella. Esta modalidad de descentralización deviene de la facultad que la Constitución Política de Colombia establece al permitir que particulares ejerzan funciones públicas, y por ende funciones administrativas, así: los artículos 123, 210,267, 365, entre otros de la Suprema Norma previenen esta posibilidad, ajustada al ordenamiento legal, que con la Ley 489 de 1998 establece la posibilidad de que un particular ejerza funciones administrativas regulando su ejercicio, cumpliendo unas condiciones y bajo unos requisitos que se determinan a partir del artículo 110 de la norma legal.

Es importante establecer cuál puede considerarse el núcleo esencial de la autonomía territorial. Bajo el contexto referido se puede afirmar que dicho núcleo se materializa en la autonomía política o de autogobierno, y la autonomía fiscal.

Se debe entender que la autonomía política o de autogobierno no es otra cosa que la posibilidad que tienen las entidades territoriales de elegir sus propios dirigentes individuales o colegiados, acatando las instrucciones que se impartan desde el centro.

Y en cuanto a la autonomía fiscal es importante aclarar que las entidades territoriales tienen un límite en este aspecto, toda vez que no cuentan con plenas facultades para la constitución e imposición de tributos, por ejemplo, ya que para poderlo hacer el tributo que pretendan implantar debe estar creado en una ley.

Lo anterior debe ser tenido en cuenta por parte de las entidades territoriales, siempre bajo el parámetro del principio de la legalidad, conforme a lo que establece el numeral 12 del artículo 150 y el numeral 4 de los artículos 300 y 313, así como el artículo 338 de la Constitución Política.

No obstante, la Corte Constitucional estableció la prohibición de que mediante una norma de tipo jurídico legal se procediera a establecer exenciones o tratamientos preferenciales que tuvieran que ver con las rentas tributarias territoriales, al igual que los recargos sobre los impuestos, salvo lo normado en el artículo 294 de la Carta respecto de la contribución por valorización (C.Const., C-004/1993). 
Para ello, la Corporación realizó una clasificación de los recursos con los que las entidades territoriales pueden cumplir sus cometidos estatales, la cual los divide respectivamente en (i) recursos de orden endógeno, es decir, los recursos propios, y (ii) recursos de orden exógeno, esto es, los que reciben del poder central, tales como transferencias, rentas cedidas, los derechos de participación de las regalías y las compensaciones. En los primeros al legislador no se le permite tener injerencia, mientras que en los segundos puede tenerla bajo los principios de razonabilidad y proporcionalidad de cada medida en concreto (C.Const., C-447/1998; C.Const,. C-035/2009).

\section{Entidades facultadas por la ley para constituir cajas menores}

La Carta Magna en el artículo 352 determina que "La Ley Orgánica de Presupuesto regulará lo correspondiente a la programación, aprobación, modificación, ejecución de los presupuestos de la Nación, de las entidades territoriales y de los entes descentralizados de cualquier nivel administrativo". Posteriormente el Estatuto Orgánico del Presupuesto (Decreto 111 de 1996), estableció, entre otros aspectos:

a) Los dos niveles a los cuales aplica el Estatuto o Decreto 111 de 1996, artículo 3:

Un primer nivel corresponde al presupuesto general de la Nación, compuesto por los presupuestos de los establecimientos públicos del orden nacional y el presupuesto nacional.

El presupuesto nacional comprende las ramas legislativa y judicial, el Ministerio Público, la Contraloría General de la República, la organización electoral, y la rama ejecutiva del nivel nacional, con excepción de los establecimientos públicos, las empresas industriales y comerciales del Estado y las sociedades de economía mixta.

Un segundo nivel, que incluye la fijación de metas financieras a todo el sector público y la distribución de los excedentes financieros de las empresas industriales y comerciales del Estado, y de las sociedades de economía mixta con el régimen de aquéllas, sin perjuicio de la autonomía que la Constitución y la ley les otorga.

Obsérvese que no hace mención de las entidades territoriales.

b) El "ajuste" de las entidades territoriales a la Ley Orgánica de Presupuesto:

Las entidades territoriales al expedir las normas orgánicas de presupuesto deberán seguir las disposiciones de la ley orgánica del presupuesto, adaptándolas a la organización, normas constitucionales y condiciones de cada entidad territorial. Mientras se expiden estas normas, se aplicará la ley orgánica del presupuesto en lo que fuere pertinente (Dcto. 111 de 1996 art. 109).

A más tardar el 31 de diciembre de 1996, las entidades territoriales ajustarán las normas sobre programación, elaboración, aprobación, y ejecución de sus presupuestos a las normas previstas en la ley orgánica del presupuesto. (Dcto. $111 \mathrm{de} 1996$ art. 104).

Por su parte, la Ley Anual de Presupuesto a nivel nacional cada año determina en sus disposiciones generales la facultad expresa de los organismos y entidades que conforman el presupuesto general de la nación para crear y reglamentar cajas menores, pero en ningún aparte menciona que dicha facultad aplique a las entidades territoriales, por lo que serán la Constitución y la ley las únicas que puede conferirles tal atribución.

Ahora bien, la Sala de Consulta y Servicio Civil del Consejo de Estado en sentencias del 2006 y la Agencia Nacional para la Contratación Pública Colombia Compra Eficiente, en concepto del 30 de marzo de 2013, reafirman la posibilidad de constituir mediante reglamento cajas menores, única y exclusivamente a los organismos y entidades que conforman el Presupuesto General de la Nación, arguyendo que esta es una facultad exclusiva de los destinatarios de la Ley Orgánica de Presupuesto.

Por su parte, el Consejo de Estado en sentencia del 20 de octubre de 2014 determinó lo que es un reglamento, y precisó que para que este pueda cumplir una función regulatoria debe tener autorización constitucional o legal. Así las cosas, la expedición del acto administrativo que cree y reglamente las cajas menores deberá cumplir este requisito.

Por lo anterior, no es aceptable que las entidades territoriales, amparándose en el principio de la autonomía territorial, procedan a establecer en los actos administrativos mediante los cuales aprueban el presupuesto 
anual, la facultad de reglamentar por acto administrativo la constitución y el funcionamiento de las cajas menores.

Si lo que se pretende es asimilar las ordenanzas departamentales y los acuerdos municipales por medio de los cuales se aprueban los presupuestos públicos seccionales y locales respectivamente a la Ley General de Presupuesto, y mediante la figura de la analogía constituir y reglamentar el funcionamiento de cajas menores, hay una grave equivocación.

Sin embargo, la Contraloría General de la República (Concepto 80112-EE89981 de 24 de noviembre de 2011), la Contaduría General de la Nación (Concepto 4225 del 28 de julio de 1997) y el Ministerio de Hacienda y Crédito Público (Consultas 2-2015-0049-05 de febrero de 2015 y 1-2014-076457 de noviembre de 2014) coinciden en afirmar que las entidades territoriales sí tienen competencia para expedir reglamentación tendiente a la constitución y funcionamiento de cajas menores, pero en todos y cada uno de los conceptos se limitan a señalar los principios generales del presupuesto público, sin indicar la facultad que la ley ha establecido para tal efecto.

La falta de precisión normativa referente a la constitución y reglamentación de las cajas menores por parte de las entidades territoriales las ha llevado, ante la necesidad de disponer de fondos con los cuales atender necesidades inmediatas, a proceder a hacerlo sustentadas en las más variadas disposiciones, como se pone de presente en la tabla 1. 
TABLA 1

Normatividad aplicada en algunas entidades territoriales para la constitución y reglamentación de cajas menores

\begin{tabular}{|c|c|c|}
\hline Departamento & $\begin{array}{l}\text { Acto administrativo que } \\
\text { adopta la caja menor }\end{array}$ & Normatividad en que sustenta el acto administrativo \\
\hline Caldas & $\begin{array}{l}\text { Decreto } 0393 \text { del } \\
10 / 11 / 2014\end{array}$ & $\begin{array}{l}\text { - Artículo } 2 \text { del Decreto } 111 \text { de } 1996 \\
\text { - } \quad \text { Artículo } 110 \text { del Decreto } 111 \text { de } 1996 \\
\text { - Artículo } 100 \text { de la Ordenanza } 601 \text { de } 2008 \text {, Estatuto Orgánico } \\
\text { del Presupuesto de Caldas }\end{array}$ \\
\hline Casanare & $\begin{array}{l}\text { Decreto } 0064 \text { del } \\
28 / 03 / 2016\end{array}$ & $\begin{array}{l}\text { - Artículo } 287 \text {, numeral 3, de la C.P. } \\
\text { - } \quad \text { Aecreto } 2768 \text { de } 2012 \text { de la Presidencia de la República } \\
\text { - } \\
\text { cual se faculta al Gobernador, para expedir decreto a fin de } \\
\text { reglamentar las cajas menores. } \\
\text { - Artículo } 16 \text { del Decreto } 05 \text { del } 10 \text { de diciembre de } 2015 \text {, se } \\
\text { establece que el Gobemador y todos los secretarios puede } \\
\text { expedir decreto de reglamentación de cajas menores. } \\
\text { - Resolución } 0497 \text { del } 31 \text { de julio de } 2014 \text {, que expidio el } \\
\text { manual de politicas y prácticas contables de la Gobernación } \\
\text { del Casanare, numeral } 6.2 \text {, capitulo } 2 \text {. }\end{array}$ \\
\hline Córdoba & $\begin{array}{l}\text { Res. No. } 0018 \text { del } 30 / 01 / \\
2014\end{array}$ & $\begin{array}{l}\text { - Artículo } 19 \text { de la Ley } 1687 \text { de } 2013 \text {, por medio de la cual se } \\
\text { decretó el presupuesto de rentas y recursos de capital en el } \\
\text { Sector Central del Estado colombiano. } \\
\text { - Decreto } 2768 \text { de } 2012 \text { de la Presidencia de la República. }\end{array}$ \\
\hline Risaralda & $\begin{array}{l}\text { Res. No. 014 del } \\
15 / 01 / 2014\end{array}$ & $\begin{array}{l}\text { - Artículo } 16 \text { de la Ordenanza } 020 \text { de } 2013 \text {, por medio de la } \\
\text { cual se fija el prepuesto general de rentas y gastos para el } \\
\text { Departamento de Risaralda, vigencia fiscal de } 2014 \text {. }\end{array}$ \\
\hline San Andrés & $\begin{array}{l}\text { Res. No. } 000859 \text { del } \\
08 / 03 / 2016\end{array}$ & $\begin{array}{l}\text { - Artículo } 305 \text { de la C.P. } \\
\text { - } \quad \text { Decreto } 2768 \text { de } 2012 \text { de la Presidencia de la República. } \\
\text { - } \quad \text { Artículo } 287 \text { de la C.P. }\end{array}$ \\
\hline $\begin{array}{l}\text { Barranca de Upía } \\
\text { (Meta) }\end{array}$ & $\begin{array}{l}\text { Res. No. } 018 \text { del } \\
10 / 01 / 2010\end{array}$ & $\begin{array}{ll}\text { - } & \text { Ley } 80 \text { de } 1993 \\
\text { - } & \text { Ley } 1150 \text { de } 2007 \\
\text { - } & \text { Decreto } 066 \text { de } 2008 \\
\end{array}$ \\
\hline $\begin{array}{l}\text { Chiquinquirá } \\
\text { (Boyacá) }\end{array}$ & $\begin{array}{l}\text { Res. No. } 033 \text { del } \\
12 / 01 / 2012\end{array}$ & 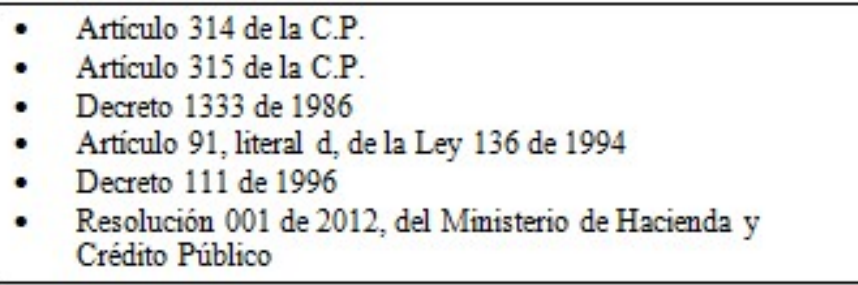 \\
\hline $\begin{array}{l}\text { Santiago de Cali } \\
\text { (Valle) }\end{array}$ & $\begin{array}{l}\text { Decreto } 411.0 .20 .0325 \\
\text { del } 31 / 05 / 2016\end{array}$ & $\begin{array}{l}\text { - Artículo } 315 \text { de la C.P. } \\
\text { - Artículo } 91 \text { de la Ley } 136 \text { de } 1994 \text {, modificado por el artículo } \\
29 \text { de la Ley } 1551 \text { de } 2012 \text {. } \\
\text { Artículos } 61 \text { y } 63 \text { del Acuerdo Municipal } 390 \text { de } 2015 \text {, por } \\
\text { medio del cual se expide el presupuesto general y recursos de } \\
\text { capital del municipio de Cali. }\end{array}$ \\
\hline Sincelejo (Sucre) & $\begin{array}{l}\text { Res. No. 0047 del 11/01/ } \\
2013\end{array}$ & - Artículo 14 del Acuerdo 105 del 10 de diciembre de 2012 . \\
\hline $\begin{array}{l}\text { Tunja } \\
\text { (Boyacá) }\end{array}$ & $\begin{array}{l}\text { Res. No. } 0042 \text { del } \\
19 / 01 / 2015\end{array}$ & $\begin{array}{l}\text { - Artículo } 315 \text { de la C.P. } \\
\text { - } \quad \text { Ley } 136 \text { de } 1994 \\
\text { - } \quad \text { Decreto } 2768 \text { de } 2012 \text { de la Presidencia de la República } \\
\text { Resolución } 001 \text { de } 2012 \text { del Ministerio de Hacienda y Crédito } \\
\text { Público }\end{array}$ \\
\hline
\end{tabular}

Fuente: elaboración propia.

Revisadas las normas jurídicas por medio de las cuales las entidades departamentales y municipales expiden los actos administrativos constitutivos de las cajas menores, se encuentra no sólo disparidad en los 
fundamentos jurídicos que invocan, sino desconocimiento de lo que aquí se ha venido reiterando: sustentar dicho acto en normas que únicamente tienen aplicabilidad para los organismos y entidades que conforman el Presupuesto General de la Nación.

Lo anterior conlleva asumir como sustento jurídico al implementar la institución de la caja menor, normas que incluso ya no tienen vigencia; así mismo, las ordenanzas departamentales y los acuerdos municipales por medio de los cuales las entidades territoriales aprueban sus presupuestos de rentas y gastos confieren a los gobernadores y alcaldes facultad para que mediante acto administrativo constituyan cajas menores, sin percatarse de que no cuentan con autorización de ley para ello, por lo que los sustentos jurídicos de tales decisiones administrativas no tienen aplicabilidad.

\section{Conclusiones}

Con todo lo anterior, podemos concluir que, si bien la descentralización que se deriva del modelo constitucional colombiano frente a la organización territorial en forma de república unitaria otorga a las entidades territoriales el goce de autonomía administrativa, este derecho no es absoluto, por cuanto debe estar sometido a los rigores de la Constitución Política y la ley. Es decir, que existen límites a la autonomía territorial en las normas jurídicas de todos los niveles jerárquicos, que no pueden ser desconocidos por los mandatarios locales y departamentales en sus actuaciones administrativas, so pena de incurrir en ilegalidades que pongan en riesgo la seguridad jurídica y la integridad financiera y contractual de los municipios.

Si las entidades territoriales deben someterse al marco constitucional y legal para el manejo de sus presupuestos públicos, es cierto también que el Estatuto Orgánico del Presupuesto prevé que la Ley General de Presupuesto permite a quienes hacen parte del Presupuesto General de la Nación la constitución y funcionamiento de cajas menores, pero hay un vacío con respecto a los entes territoriales puesto que estos no hacen parte del presupuesto general de la nación.

Por tanto, ya que no existe norma constitucional o legal que faculte a las entidades territoriales para constituir y crear la institución jurídica de las cajas menores, estas no deberían expedir actos administrativos que crean y reglamentan cajas menores, puesto que están asimilando las ordenanzas y acuerdos por medio de los cuales se aprueban los presupuestos públicos seccionales y locales a la Ley General de Presupuesto mediante la figura de la analogía y esto es abiertamente ilegal en materia administrativa donde la discrecionalidad es limitada.

En conclusión, urge avanzar en la promulgación de una norma que haga claridad al respecto y ponga fin a la confusión existente en este aspecto, para evitar inseguridad jurídica y prevenir más ilegalidades en las actuaciones administrativas locales y departamentales.

\section{Referencias}

Agencia Nacional para la Contratación Pública Colombia Compra Eficiente. Concepto del 30 de marzo de 2013. Relativo a compras de caja menor.

Angarita G., J. (2005). Lecciones de derecho civil: personas y representación de incapaces. Bogotá: Temis

Asamblea Nacional Constituyente. (1991). Constitución Política de Colombia.

Congreso de la República. (28 de junio de 2011). Ley 1454 de 2011. Diario Oficial, No. 48.115.

Congreso de la República. (1887). Codigo Civil Colombiano.

Congreso de la República. (08 de noviembre de 1992). Ley 21 de 1992. Diario Oficial, No. 40.658.

Congreso de la República. (28 de diciembre de 1992). Ley 30 de 1992. Diario Oficial, No. 40.700.

Congreso de la República. (29 de diciembre de 1998). Ley 489 de 1998. Diario Oficial, No. 43.464.

Congreso de la República. (2016). Codigo Civil Colombiano. Bogotá: Legis. 
Corte Constitucional. Sentencia C-004/1993 (M. P.: Ciro Angarita Barón; 14 de enero de 1993).

Corte Constitucional. Sentencia C-545/1993 (M. P.: Jorge Arango Mejía; 25 de noviembre de 1993.

Corte Constitucional. Sentencia C-535/1996 (M. P.: Alejandro Martínez Caballero; 16 de octubre de 1996.

Corte Constitucional. Sentencia C-447/1998 (M. P.: Carlos Gaviria Díaz; 26 de agosto de 1998.

Corte Constitucional. Sentencia C-1258/2001 (M. P.: Jaime Córdoba Triviño; 29 de noviembre de 2001.

Corte Constitucional. Sentencia C-127/2002 (M. P.: Alfredo Beltrán Sierra; 26 de febrero de 2002.

Corte Constitucional. Sentencia C-889/2002 (M. P.: Jaime Córdoba Triviño; 22 de octubre de 2002.

Corte Constitucional. Sentencia C-063/2005 (M. P.: Jaime Araújo Rentería; 1 de febrero de 2005.

Corte Constitucional. Sentencia C-035/2009 (M. P.: Marco Gerardo Monroy Cabra; 27 de enero de 2009.

Corte Constitucional. Sentencia C-149 de 2010 (M. P.: Jorge Iván Palacio Palacio; 04 de marzo de 2010.

Consejo de Estado. Sala de Consulta y Servicio Civil. Sentencia rad. 11001-03-06-000-2006-000-23-00 (1724) del 20 de febrero de 2006.

Consejo de Estado. Sala de Consulta y Servicio Civil. Sentencia rad. 11001-0306-000-2006-000-30-00(1731) del 14 de marzo de 2006.

Consejo de Estado. Sala de Consulta y Servicio Civil. Sentencia rad.11001-03-26-000-2008-00087-00 del 20 de octubre de 2014.

Contaduría General de la Nación. Concepto 4225 del 28 de julio de 1997. Relativo a manejo de cajas menores en las entidades públicas.

Contraloría General de la República. Concepto 80112-EE89981 de 24 de noviembre de 2011. Relativo a contratación con recursos de la caja menor -consulta del SICE- viabilidad.

Henao, H. J. (2015). El Poder Municipal, 17 ed. Bogotá: Escuela Superior de Administración Pública.

Ministerio de Hacienda y Crédito Público. Consulta No. 2-2015-0049-05 del 1 de febrero de 2015. Relativa a normas orgánicas de presupuesto.

Ministerio de Hacienda y Crédito Público. Consulta 1-2014-076457 de noviembre de 2014. Relativa a Normas Orgánicas de Presupuesto-Cajas menores.

Presidente de la República. (2 de abril de 1993). Decreto 663 de 1993. Diario Oficial, No. 40.820.

Presidente de la República. (18 de abril de 1968). Decreto Ley 1222 de 1986. Diario Oficial, No. 37.498.

Presidente de la República. (25 de abril de 1986). Decreto Ley 1333 de 1986. Diario Oficial, No. 37.466.

Presidente de la República (15 de enero de 1996). Decreto 111 de 1996. Diario Oficial, No. 42.692.

Rodríguez, G. H. (1995). Derecho Administrativo General, 2a ed., Bogotá: Ciencia y Derecho.

Rodríguez C., J. P. (2014). El principio de la autonomía territorial de los municipios y los departamentos en Colombia, análisis y perspectivas desde la jurisprudencia de la Corte Constitucional 1992-2012. Summa Iuris, 2(2), 275-302. https://doi.org/10.21501/issn.2339-4536

Rodríguez R., L. (2012). Estructura del Poder Público en Colombia. Bogotá: Temis S.A.

Rodríguez R., L. (2013). Derecho Administrativo General y Colombiano, 18 ed. Bogotá: Temis.

\section{Notas}

*Artículo de reflexión.

\section{Licencia Creative Commons CC BY 4.0}

Para citar este artículo: Lucas O., C. A. (2018). Constitución de cajas menores en entidades territoriales. Un límite a la discrecionalidad administrativa. Cuadernos de Contabilidad, 19(48), 1-12. https:// doi.org/10.1 1144/Javeriana.cc19-48.ccme 